\title{
Modulation of $\beta$-amyloid by a single dose of GSK933776 in patients with mild Alzheimer's disease: a phase I study
}

Thomas Leyhe ${ }^{1,2+}$, Niels Andreasen ${ }^{3 \dagger}$, Monica Simeoni ${ }^{4+}$, Arno Reich ${ }^{5+}$, Christine AF von Arnim ${ }^{6+}$, Xin Tong ${ }^{7 \dagger}$, Astrid $\mathrm{YeO}^{8 \dagger}$, Shahid Khan ${ }^{8 \dagger}$, Amy Loercher ${ }^{9 \dagger}$, Michelle Chalker ${ }^{10 \dagger}$, Charles Hottenstein ${ }^{11 \dagger}$, Henrik Zetterberg ${ }^{12,13 \dagger}$, Jan Hilpert ${ }^{14 \dagger}$ and Prafull Mistry ${ }^{15^{*}+}$

\begin{abstract}
Introduction: In this study, we evaluated the safety and pharmacodynamic effects of the Fc-inactivated anti- $\beta$-amyloid (anti-A $\beta$ ) monoclonal antibody GSK933776 in patients with mild Alzheimer's disease and mild cognitive impairment. $A \beta$ and tau levels were investigated in cerebrospinal fluid (CSF), and the relationship between $A \beta$ levels and $A \beta$ modulation in plasma was explored. The feasibility of a continuous sampling method using a lumbar catheter was assessed.

Methods: This trial was a phase I, open-label, uncontrolled, single-dose, exploratory experimental medicine study of intravenous GSK933776 at doses of $1 \mathrm{mg} / \mathrm{kg}, 3 \mathrm{mg} / \mathrm{kg}$ or $6 \mathrm{mg} / \mathrm{kg}$ ( $n=6 / \mathrm{group}$ ). The time course of plasma and CSF concentrations of GSK933776 and A 3 was assessed. Sample size was based on feasibility, and no formal statistical analyses were performed.

Results: Following administration of GSK933776 at doses of $1 \mathrm{mg} / \mathrm{kg}, 3 \mathrm{mg} / \mathrm{kg}$ and $6 \mathrm{mg} / \mathrm{kg}$, there were decreases from baseline in CSF $A \beta_{1-42}$ (from 0 to 12 hours) by $22.8 \mathrm{pg} / \mathrm{ml}(6.2 \%), 43.5 \mathrm{pg} / \mathrm{ml}(9.2 \%)$ and $60.5 \mathrm{pg} / \mathrm{ml}(12.5 \%)$, respectively. Plasma concentrations of total $A \beta_{18-35}$ and $A \beta_{42} 28-42$ increased immediately after infusion and CSF tau concentration increased slightly, but did not significantly change, following administration of all doses of GSK933776. Pharmacokinetics confirmed the presence of GSK933776 in the CSF, which exhibited a dose-response relationship. One patient underwent minor surgery without sequelae following a ruptured lumbar catheter.
\end{abstract}

Conclusion: GSK933776 demonstrated pharmacological activity and target engagement in CSF and plasma, and the continuous sampling method via a catheter successfully assessed the A $\beta$ changes following single-dose administration of GSK933776.

Trial registration: ClinicalTrials.gov Identifier: NCT01424436. Registered 4 August 2011

\section{Introduction}

Aggregated $\beta$-amyloid peptide $(A \beta)$ is the hallmark of Alzheimer's disease (AD) brain pathology. As $A \beta$ plaques are one of the underlying pathological features of $\mathrm{AD}$, significant research efforts have been directed at developing antiamyloid therapies to clear or neutralise the amyloid peptide's toxic forms $[1,2]$. Immunotherapeutic approaches

\footnotetext{
* Correspondence: prafull.c.mistry@gsk.com

${ }^{\dagger}$ Equal contributors

${ }^{15}$ Quantitative Sciences, GlaxoSmithKline, Gunnels Wood Road, Stevenage, Hertfordshire SG1 2NY, UK

Full list of author information is available at the end of the article
}

for the treatment of $\mathrm{AD}$ include active immunisation, whereby an $A \beta$ peptide, or a fragment of it, is administered, which produces an immune response against $A \beta$. Activation of both cellular and humoral immunity follows, which clears amyloid deposits from the brain. Passive immunisation involves administration of exogenous, specific monoclonal antibodies against $A \beta$ which may treat $A D$ by acting centrally on amyloid plaques in the brain or peripherally through an $A \beta$ "peripheral sink" mechanism. By the peripheral sink mechanism, circulating antibodies sequester $A \beta$ and favour efflux of $A \beta$ from the central nervous system (CNS) over influx to the CNS [3]. 
Immunotherapy using monoclonal antibodies directed against $A \beta$ is considered to be the preferred method in the search for mechanistic disease-modifying treatments for AD. The key element for an immunotherapy during early clinical development is to demonstrate that the agent engages its target. In the case of anti- $A \beta$ antibodies, the preferred target is the CNS. During the development of the human anti- $\mathrm{A} \beta$ antibody gantenerumab, it was initially demonstrated in mice that the antibody bound specifically to $A \beta$ plaques [4]. In an ascending-dose, positron emission tomographic study of patients with $\mathrm{AD}$ and in ex vivo studies of human brain slices taken from patients who had $\mathrm{AD}$, gantenerumab treatment resulted in reduction of brain $A \beta$ levels, indicating that antibody- $A \beta$ complexes had formed [4]. Cerebrospinal fluid (CSF) examinations conducted in patients with $\mathrm{AD}$ following administration of solanezumab, another human anti-A $\beta$ antibody, showed a dose-dependent increase in unbound CSF $A \beta_{1-42}$, suggesting that this antibody shifted the $A \beta$ equilibrium sufficiently to mobilise $A \beta_{1-42}$ from amyloid plaques [5].

Two approaches are being used in AD clinical trials to obtain CSF samples to assess drug penetration and target engagement in the CNS. The lumbar puncture technique relies on sampling at two different time points and was used to determine CSF A $\beta$ levels and drug concentrations in a solanezumab phase II study [5]. Alternatively, CSF samples can be taken continuously by using a catheter, as demonstrated in a previous study, to measure $A \beta$ production and clearance in the CNS directly [6,7].

GSK933776 is a humanised mouse anti-human $A \beta$ IgG1 monoclonal antibody that binds with high affinity to the $A \beta N$ terminus and has the $\mathrm{Fc}$ region engineered to substantially reduce the fixation of complement and Fc receptor binding, which is responsible for humoral adaptive immunity and cell-mediated tissue damage.

Herein we present the results of an exploratory experimental medicine study conducted to assess the effects of a single-dose exposure of GSK933776 on A $\beta$ levels in CSF, as well as its relationship with $A \beta$ modulation, in the plasma of patients with mild $\mathrm{AD}$ and mild cognitive impairment (MCI). We assessed the time course and dose-dependency of $A \beta$ and tau changes in the first 12 hours after administration of GSK933776 as well as the feasibility of using lumbar catheters to assess these changes. The choice of dose ranges tested in this study was driven by pharmacodynamics detected in a previous study conducted in patients with AD. GSK933776 administered in three repeat doses every 4 weeks at $\geq 0.1$ $\mathrm{mg} / \mathrm{kg}$ lowered free $A \beta$ concentrations in plasma. For total $A \beta_{1-42}$, the final peak/trough ratio was $\leq 2$ at GSK933776 $\geq 3 \mathrm{mg} / \mathrm{kg}$. For total $A \beta_{18-35}$, the final peak/ trough ratio was $\leq 2$ at $6 \mathrm{mg} / \mathrm{kg}$ (manuscript in submission). The results of our present study will support the dose selection for subsequent larger-scale clinical studies assessing the effect of GSK933776 on cognitive, global and functional endpoints.

\section{Methods}

\section{Study protocol}

The study protocol was reviewed and approved by the following ethics committees: Medizinische Ethik-Kommission II, der Medizinischen Fakultät Mannheim, Mannheim, Germany; Ethik-Kommission der Medizinischen Fakultät und am Universitätsklinikum Tübingen, Germany; and Regionala Etiksprovningsnamnden Stockholm, Stockholm, Sweden. The study was conducted in accordance with Good Clinical Practice and the 2008 Declaration of Helsinki. All patients provided written, informed consent to participate in the study and, separately, to undergo genetic analysis.

\section{Study population}

Men and nonfertile women ages 50 to 85 years with a clinical diagnosis of probable mild AD, Mini Mental State Examination (MMSE) score of 20 to 26 [8] or MCI were included. All patients demonstrated a decrease in $\mathrm{A} \beta_{1-42}$ to $<550 \mathrm{pg} / \mathrm{ml}$ in CSF and increases in total $\mathrm{T}$ tau to $>400 \mathrm{pg} / \mathrm{ml}$ or phosphorylated tau 181 to $>70 \mathrm{pg} / \mathrm{ml}$ in CSF, which are indicative of prodromal or mild $\mathrm{AD}$ $[9,10]$. The term prodromal Alzheimer's disease is used to describe patients who have a hippocampal type of amnestic disorder and a biomarker indicative of the presence of $\mathrm{AD}$, but who are not functionally impaired and do not meet the criteria for Alzheimer's dementia [11,12]. The definition of prodromal $\mathrm{AD}$ is similar to that of $\mathrm{MCI}$ based on the classification criteria proposed by the National Institute on Aging and Alzheimer's Association work group [13].

The inclusion criteria for entry into this trial were that patients had to be in good health, determined on the basis of routine clinical laboratory test screening results, physical examinations, vital signs and 12-lead electrocardiograms (ECGs). Exclusion criteria included a history or evidence of any other CNS disorder that could be interpreted as a cause of dementia; Hachinski Ischemic Scale score $>4$; a magnetic resonance imaging (MRI) scan not consistent with $\mathrm{AD}$ or evidence of any other CNS condition; minimal vascular changes or more than three microhaemorrhagic lesions; and a history of psychiatric illness, cerebral haemorrhage, seizures or strokes during the 3 years preceding the study; and cardiovascular disease or diabetes.

\section{Study design}

Recruitment of patients into this open-label, single-dose study (protocol number BA1113043, Clinicaltrials.gov Identifier NCT01424436) was carried out from May 2010 to December 2011 at three sites in Germany and 
two in Sweden. Patients were screened on day -30 prior to dosing and randomised to receive doses of GSK933776. The patients were assigned to receive doses of GSK933776 in accordance with the randomisation schedule produced using RandAll, a web server-based clinical trials system. The doses of GSK933776 were $1 \mathrm{mg} / \mathrm{kg}, 3 \mathrm{mg} / \mathrm{kg}$ or $6 \mathrm{mg} /$ $\mathrm{kg}$ ( $n=6$ per group) administered by intravenous pump infusion for 1 hour. Patients were followed for up to 56 days postdosing.

The primary endpoint was measurement of the levels and temporal changes of $A \beta_{1-42}$ in CSF after administration of GSK933776 in patients with mild AD and MCI. Secondary endpoints were measurement of the levels and temporal changes following GSK933776 administration of the following: total $A \beta 42_{28-42}$ and $A \beta_{18-35}$ in plasma and tau and phosphorylated tau 181 in CSF, the pharmacokinetics for GSK933776 in CSF and plasma, the pharmacokinetic-pharmacodynamic (PK-PD) relationship of GSK933776 in CSF and plasma and the safety and tolerability of GSK933776.

\section{Pharmacodynamics sample collection and analysis}

For the first four patients who received the lowest dose (1 $\mathrm{mg} / \mathrm{kg}$ ), blood and CSF samples were collected at hourly intervals over a 30-hour time period from approximately 11 hours predosing to 19 hours postdosing. The primary sampling time period for evaluation of baseline levels was 6 to 8 hours predosing, whereby 0 to 5 hours postdosing was considered a run-in period during which we obtained stable values. The time period from 0 to 12 hours postdosing was the focus for the postdosing assessment. This duration was initially based on plasma pharmacodynamics observed in our previous study, that is, the time of onset of lowering of free $A \beta$ (manuscript in submission). After the first four patients completed the protocol, their A $\beta$ levels were reviewed and the sample collection times for CSF and blood for both baseline and postdosing were adjusted as follows. CSF samples were collected hourly (3 $\mathrm{ml}$ per sample) from 9 hours predosing to 12 hours postdosing. Blood samples were collected hourly from 6 hours predosing to 12 hours postdosing and at follow-up: once on day 7 and once on day 56 postdosing. Total tau and phosphorylated tau 181 were measured in CSF at 5 hours predosing, at the time of dosing and at 5 hours and 12 hours postdosing. Because of the short-term exposure to GSK933776, no changes in total tau or phosphorylated tau 181 were expected.

Insertion of the lumbar catheter was done according to local hospital protocols. Continuous CSF collection was performed according to the standard operating procedures of the study and carried out by medical staff trained in this procedure. CSF $\mathrm{A} \beta_{1-42}$, total tau and phosphorylated tau 181 were measured using INNOTEST kits (Innogenetics/Fujirebio Europe, Ghent, Belgium). For the
INNOTEST assay for $A \beta_{1-42}$, we used $21 F 12$ as a coating monoclonal antibody, which is specific for the C-terminal epitope 42, and 3D5 as a detection antibody, which is specific to N-terminal epitope 1 . The INNOTEST assay for phosphorylated-tau 181 uses HT7 as a coating antibody, which is specific for amino acids 159 to 163, and AT270 as a detection antibody, which is specific to phosphorylated Thr181. All CSF analyses were performed batchwise by board-certified laboratory technicians who were blinded to clinical and treatment data. Intra-assay coefficients of variation were below $10 \%$.

For plasma preparation, blood samples were processed within 30 minutes by centrifugation at 2,000 $\times g$ for 15 minutes at $4^{\circ} \mathrm{C}$ to obtain plasma. A protease inhibitor (0.02 ml; Roche Applied Science, Burgess Hill, UK) was added to $0.5 \mathrm{ml}$ of plasma. Samples were then frozen upright on dry ice or in a freezer at or below $-70^{\circ} \mathrm{C}$. The specificities of the capture and detection antibodies used in the plasma total $A \beta$ measurements (numbers in brackets indicate the minimal amino acid sequence detected by the plasma $A \beta$ assay) were as follows. The combinations of the capture antibody 6F6 (amino acids 28 to 35 , generated by GlaxoSmithKline (GSK)) and detection antibody 5G5 (amino acids 35 to 42; generated by GSK) detected all $A \beta$ fragments containing an intact $C$ terminus, such as $A \beta_{1-42}$ and $A \beta_{3-42}$, which is considered indicative of total $A \beta 42_{28-42} .6 F 6$ and the detection antibody 4G8 (amino acids 18 to 22) (SIG-39220; Covance, Emeryville, CA, USA) detected A $\beta$ fragments containing the amino acid sequence 18 to 35 , including $A \beta_{1-38}, A \beta_{1-40}$ and $A \beta_{1-42}$, which are considered indicative of total $A \beta_{18-35}$. Total assays detected both free and GSK933776-bound A $\beta$ fragments. There was no competition between the capture antibody 6FS and GSK933776, because $6 \mathrm{~F} 6$ recognises $\mathrm{A} \beta$ amino acids 28 to 35 and GSK933776 recognises $A \beta$ amino acids 1 to 5 . Total levels of $A \beta_{18-35}$ and total $A \beta 42_{28-42}$ were measured in plasma only.

\section{Pharmacokinetics sample collection and analysis}

Blood samples were collected once prebaseline, once during GSK933776 administration, hourly for 4 hours postdosing and then $6,8,10$ and 12 hours postdosing as well as at follow-up 7 and 56 days postdosing. CSF samples were collected every hour over a total period of 22 hours, beginning 9 hours predosing and ending 12 hours postdosing. Approximately $0.5 \mathrm{ml}$ of CSF and approximately $3 \mathrm{ml}$ of whole blood were collected at every time point.

Concentrations of GSK933776 were determined in plasma and CSF samples using an immunoassay that detects free GSK933776 antibody. Briefly, the humanized monoclonal antibody drug specific to GSK933776 is captured with a $\mathrm{A} \beta$ fragment immobilized on a microtitre 
plate. The plate was washed removing all nonspecific material and GSK933776 is detected using an anti-human IgG (Fc specific) monoclonal antibody conjugated to a reporter tag which is developed and detected by immunoelectrochemiluminescence, resulting in a quantifiable response.

Pharmacokinetics analyses of plasma and CSF GSK933776 were calculated by standard noncompartmental analysis using WinNonlin Pro 5.2 software (Pharsight, Mountain View, CA, USA) and were based on actual sampling times. The following parameters were measured: the first occurrence of the maximum observed plasma and CSF concentrations determined directly from raw concentration-time data $\left(C_{\max }\right)$; the time at which $C_{\max }$ was observed, which was determined directly from raw concentration-time data $\left(t_{\max }\right)$; the area under the plasma and CSF concentration-time curve to the last quantifiable concentration $\left(\mathrm{AUC}_{0-t}\right)$; the area under the plasma and CSF concentration-time curve from time 0 to 12 hours postdosing $\left(\mathrm{AUC}_{0-12}\right)$; the time of the last observed plasma concentration $\left(t_{\text {last }}\right)$; and the concentration at $t_{\text {last }}\left(C_{\mathrm{t}}\right)$. The following additional parameters were included for analysis of CSF pharmacokinetics: the areas under the CSF concentration-time curve from time 0 to 4 hours postdosing $\mathrm{AUC}_{0-4}$ and from 5 to 12 hours postdosing $\mathrm{AUC}_{5-12}$ and the time prior to the first measurable (that is, nonzero) concentration in CSF $\left(t_{\mathrm{lag}}\right)$.

\section{Safety assessments}

Clinical chemistry and haematology tests, vital signs, 12-lead ECG readings and brain MRI were performed at screening, at intervals throughout the study and at follow-up examinations. Adverse events were coded using the Medical Dictionary for Regulatory Activities (http:// www.meddra.org/) criteria.

\section{Statistical analysis}

As this was an exploratory experimental medicine study, we did not perform any formal calculations of power or sample size. Sample sizes were chosen based on feasibility to allow preliminary evaluations of the safety and effects GSK933776 on $A \beta$ and tau levels in CSF. No formal statistical analyses were performed.

\section{Pharmacodynamics analyses}

CSF A $\beta$ parameters were summarised using standard descriptive statistics for a range of summary measures (absolute, absolute change from baseline, absolute percent change from baseline, weighted mean, weighted mean change from baseline and weighted mean percent change from baseline) and are presented in individual participant plots. The weighted means were derived by calculating the AUCs using the trapezoidal rule and then dividing by the actual relevant time interval. CSF parameters (tau and phosphorylated tau 181) and plasma parameters $\left(A \beta_{18-35}\right.$ and $\left.A \beta 42_{28-42}\right)$ were summarised (absolute) and are presented in individual participant plots Additional file 1 and Additional file 2, respectively.

\section{Pharmacokinetics analyses}

Concentrations of GSK933776 in plasma and CSF were summarised using standard summary statistics. Noncompartmental plasma pharmacokinetics parameters were summarised using standard descriptive statistics, which also included coefficients of variation, geometric means and $95 \%$ confidence intervals, for the geometric means.

\section{Results}

\section{Patient disposition and baseline characteristics}

Twenty-six patients were screened. Nine patients were excluded because they failed to meet the inclusion criteria, and two withdrew before dosing began (Figure 1). Fifteen patients received GSK933776. Three of the fifteen patients received GSK933776 at two dose levels. One patient received $1 \mathrm{mg} / \mathrm{kg}$ and $3 \mathrm{mg} / \mathrm{kg}$ one received $1 \mathrm{mg} / \mathrm{kg}$

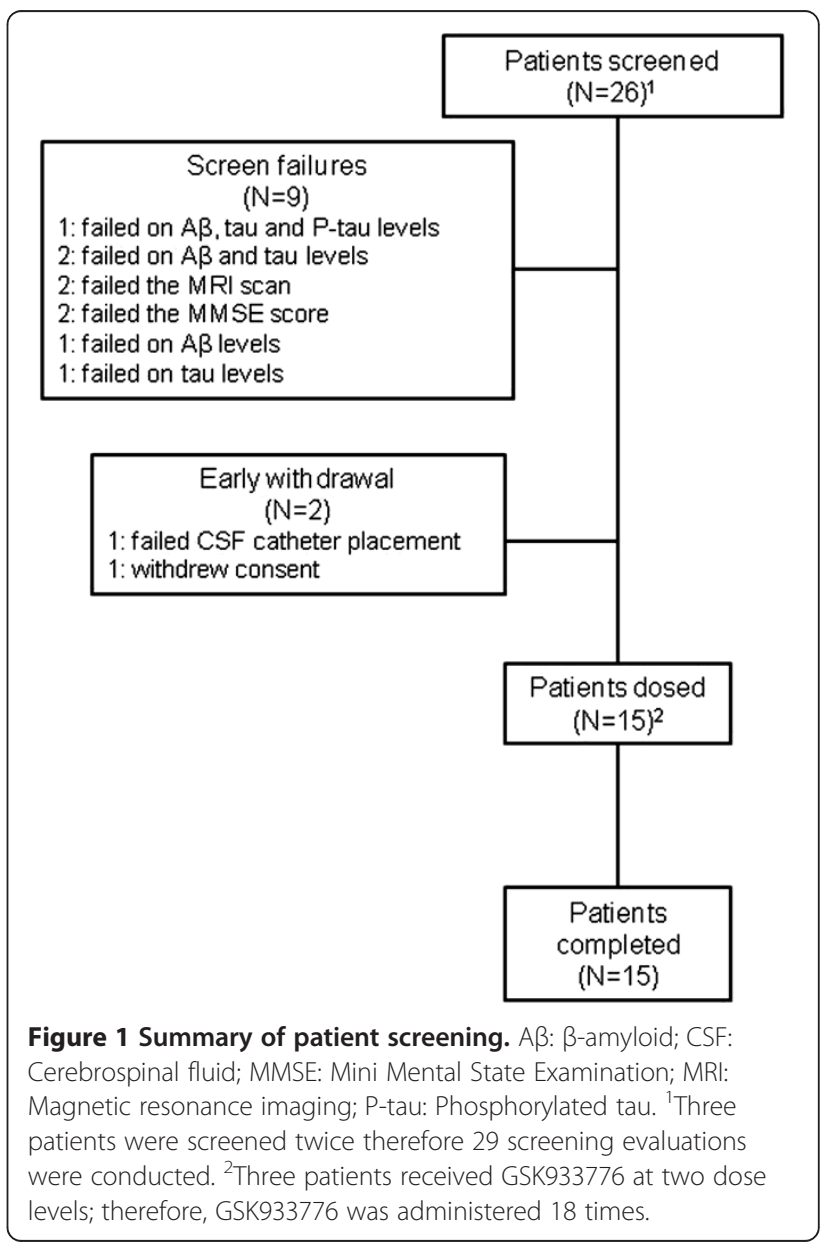


Table 1 Summary of patient baseline characteristics ${ }^{a}$

\begin{tabular}{|c|c|c|c|c|}
\hline \multirow[b]{2}{*}{ Demographic characteristics } & \multirow[b]{2}{*}{ Sex } & \multicolumn{3}{|c|}{ GSK933776 dose } \\
\hline & & $1 \mathrm{mg} / \mathrm{kg}(n=6)$ & $3 \mathrm{mg} / \mathrm{kg}(n=6)$ & $6 \mathrm{mg} / \mathrm{kg}(n=6)$ \\
\hline Mean age (yr) (range) & & 69.0 (61 to 79$)$ & 68.3 (57 to 79$)$ & 66.0 (58 to 77) \\
\hline \multirow[t]{2}{*}{ Sex, $n(\%)$} & Female & $2(33)$ & $5(83)$ & $3(50)$ \\
\hline & Male & $4(67)$ & $1(17)$ & $3(50)$ \\
\hline Race, $n(\%)$ & Caucasian & $6(100)$ & $6(100)$ & $6(100)$ \\
\hline Mean BMI kg/m² (range) & & 23.7 (20 to 26) & 23.5 (21 to 28$)$ & 25.4 (22 to 27$)$ \\
\hline \multirow[t]{4}{*}{ APOE $\varepsilon 4$ status, $n(\%)$} & E2E3 & $0(0)$ & $0(0)$ & $0(0)$ \\
\hline & E3E3 & $1(17)$ & $0(0)$ & $0(0)$ \\
\hline & E3E4 & $3(50)$ & $2(40) / 1^{b}$ & $3(75)^{c}$ \\
\hline & E4E4 & $2(33)$ & $3(60)$ & $1(25)$ \\
\hline
\end{tabular}

${ }^{a}$ BMI: Body mass index. ${ }^{b}$ One participant who entered the study and provided pharmacogenetics (PGx) consent and a sample in the $1 \mathrm{mg} / \mathrm{kg}$ dosing arm reentered the study in the $3 \mathrm{mg} / \mathrm{kg}$ dosing arm. The PGx consent and sample were obtained again unnecessarily for the $3 \mathrm{mg} / \mathrm{kg}$ dosing. The second PGx sample was subsequently destroyed to maintain consistency within the study by collecting and using only one sample per individual. 'Two participants who had entered the study and provided PGx consent and a sample in the $3 \mathrm{mg} / \mathrm{kg}$ dosing arm reentered the study in the $6 \mathrm{mg} / \mathrm{kg}$ dosing arm. The PGx consent and sample were not obtained again for these patients.

and $6 \mathrm{mg} / \mathrm{kg}$ and one received $3 \mathrm{mg} / \mathrm{kg}$ and $6 \mathrm{mg} / \mathrm{kg}$. For patients who were assigned to receive two dose levels, the time interval between the doses was approximately 5 months. Their baseline data are presented in Table 1. For the entire patient population, the mean age was 67.8 years (range: 57 to 70 years) and the mean body mass index was $24.18 \mathrm{~kg} / \mathrm{m}^{2}$ (range: 19.6 to 27.7). Nine patients were female and six were male, and all were Caucasians. Most patients carried the APOE \&4 allele (14 (93\%) of 15 patients), and six of these patients carried two copies of the allele.

Mean \pm standard deviation (SD) CSF concentrations for phosphorylated tau 181 were $90.6 \pm 39.36 \mathrm{pg} / \mathrm{ml}$ for the GSK933776 $1 \mathrm{mg} / \mathrm{kg}$ group $(n=4), 71.0 \pm 39.75 \mathrm{pg} / \mathrm{ml}$ for $3 \mathrm{mg} / \mathrm{kg}(n=5)$ and $153.9 \pm 37.37 \mathrm{pg} / \mathrm{ml}$ for $6 \mathrm{mg} / \mathrm{kg}$ $(n=6)$. Mean $( \pm S D)$ CSF concentrations for tau were $828.3 \pm 430.29 \mathrm{pg} / \mathrm{ml}$ for the GSK933776 $1 \mathrm{mg} / \mathrm{kg}$ group $(n=4), 668.2 \pm 262.35 \mathrm{pg} / \mathrm{ml}$ for $3 \mathrm{mg} / \mathrm{kg}(n=5)$ and $1,209.3 \pm 262.35 \mathrm{pg} / \mathrm{ml}$ for $6 \mathrm{mg} / \mathrm{kg}(n=6)$. Baseline data for patient CSF $\mathrm{A} \beta_{1-42}$ levels are presented in Table 2.

\section{Pharmacodynamics}

Following administration of GSK933776 $1 \mathrm{mg} / \mathrm{kg}, 3 \mathrm{mg} / \mathrm{kg}$ and $6 \mathrm{mg} / \mathrm{kg}$, average apparent decreases from baseline in total CSF $\mathrm{A} \beta_{1-42}$ (0 to 12 hours) of $22.8 \mathrm{pg} / \mathrm{ml}(6.2 \%), 43.5$ $\mathrm{pg} / \mathrm{ml}(9.2 \%)$ and $60.5 \mathrm{pg} / \mathrm{ml}$ (12.5\%), respectively (Table 2 ). We observed greater decreases from 5 to 12 hours and lesser decreases from 0 to 4 hours compared with CSF $A \beta_{1-42}$ (0 to 12 hours) across the dose ranges. Among individual patients, decreases from baseline in CSF $A \beta_{1-42}$ were observed across the sampling periods after administration of GSK933776 at all dose levels. Decreases were most marked at the $6 \mathrm{mg} / \mathrm{kg}$ dose (Figure 2).

We observed increases in plasma concentrations of total $\mathrm{A} \beta_{18-35}$ and total $\mathrm{A} \beta 42_{28-42}$ following administration of GSK933776 at $1 \mathrm{mg} / \mathrm{kg}, 3 \mathrm{mg} / \mathrm{kg}$ and 6 $\mathrm{mg} / \mathrm{kg}$ doses, which began immediately after infusion (Figure $3 \mathrm{~A}$ and 3B). Increases at the $3 \mathrm{mg} / \mathrm{kg}$ and $6 \mathrm{mg} / \mathrm{kg}$ dose levels were slightly greater than those after the $1 \mathrm{mg} / \mathrm{kg}$ dose.

Table 2 Summary statistics of decreases from baseline in cerebrospinal fluid $A \beta_{1-42}$ following administration of GSK933776 $^{\text {a }}$

\begin{tabular}{|c|c|c|c|c|c|}
\hline Sampling time (h) & GSK933776 ( $n=6 /$ dose) & Baseline $^{\mathbf{b}}$ & Postdosing & Change (\%) & $95 \% \mathrm{Cl}$ \\
\hline \multirow[t]{3}{*}{0 to 4} & $1 \mathrm{mg} / \mathrm{kg}$ & $363.4 \pm 60.1$ & $350.2 \pm 61.7$ & -3.6 & $(-10.8$ to 3.6$)$ \\
\hline & $3 \mathrm{mg} / \mathrm{kg}$ & $479.2 \pm 65.8$ & $446.4 \pm 70.8$ & -6.8 & $(-14.9$ to 1.2$)$ \\
\hline & $6 \mathrm{mg} / \mathrm{kg}$ & $502.7 \pm 71.1$ & $456.1 \pm 88.9$ & -9.7 & $(-15.4$ to -3.9$)$ \\
\hline \multirow[t]{3}{*}{5 to 12} & $1 \mathrm{mg} / \mathrm{kg}$ & $363.4 \pm 60.1$ & $333.9 \pm 52.1$ & -7.9 & $(-12.6$ to -3.2$)$ \\
\hline & $3 \mathrm{mg} / \mathrm{kg}$ & $479.2 \pm 65.8$ & $428.9 \pm 77.1$ & -10.7 & $(-20.2$ to -1.2$)$ \\
\hline & $6 \mathrm{mg} / \mathrm{kg}$ & $502.7 \pm 71.1$ & $433.5 \pm 85.1$ & -14.2 & $(-19.8$ to -8.6$)$ \\
\hline \multirow[t]{3}{*}{0 to 12} & $1 \mathrm{mg} / \mathrm{kg}$ & $363.4 \pm 60.1$ & $340.6 \pm 55.7$ & -6.2 & $(-11.2$ to -1.1$)$ \\
\hline & $3 \mathrm{mg} / \mathrm{kg}$ & $479.2 \pm 65.8$ & $435.7 \pm 74.4$ & -9.2 & $(-17.9$ to -0.5$)$ \\
\hline & $6 \mathrm{mg} / \mathrm{kg}$ & $502.7 \pm 71.1$ & $442.2 \pm 86.4$ & -12.5 & $(-18.0$ to -7.0$)$ \\
\hline
\end{tabular}

${ }^{\mathrm{a}} \mathrm{Cl}$ : confidence interval. Results are reported as means \pm standard deviations. ${ }^{\mathrm{b}}-6$ to -1 hours predosing. 


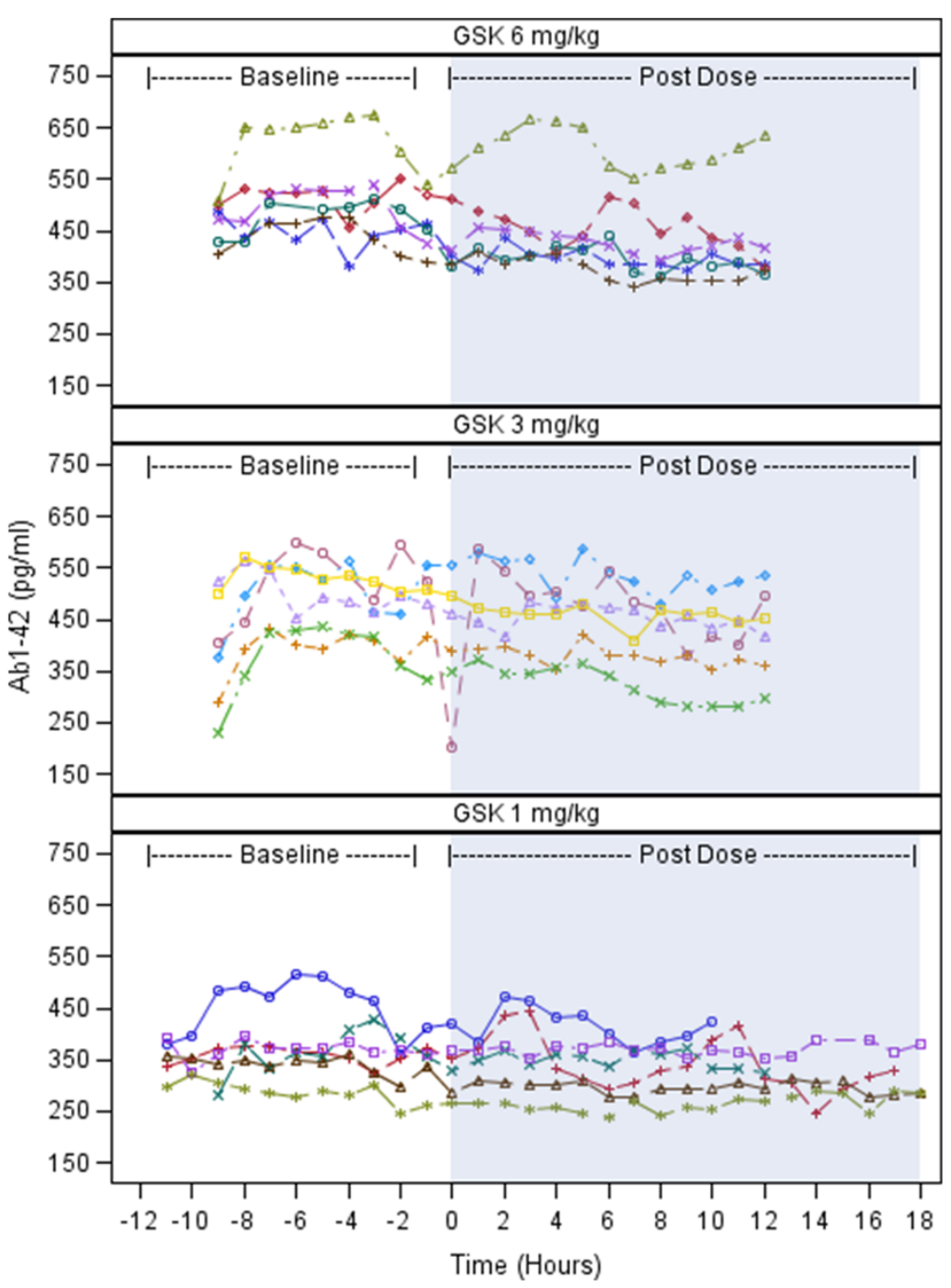

Figure 2 Plots illustrating cerebrospinal fluid $\beta$-amyloid $A b(1-42)$ levels for individuals by time and dose level for each dose group. GSK: GSK933776. Patients $=6$ per group.

Concentrations of CSF tau and phosphorylated tau 181 were variable and exhibited a small increase from baseline following administration of all three doses of GSK933776, but they did not significantly change (see Additional file 1 and Additional file 2, respectively). Three patients who received $1 \mathrm{mg} / \mathrm{kg}$ GSK933776 underwent sampling for tau for 18 hours. By 12 hours in these patients, the levels of tau appeared to have increased slightly, then plateaued and then began to decrease.

\section{Pharmacokinetics}

Because the CSF pharmacokinetics data were minimal, median values were considered more appropriate to summarise (Table 3 ). The $t_{1 / 2}$ parameter could not be determined, because there were insufficient CSF and plasma samples to characterise adequately the switch from the first to the terminal exponential phase. Median exposure in the CSF was higher at $6 \mathrm{mg} / \mathrm{kg}$ than at
$1 \mathrm{mg} / \mathrm{kg}$ and $3 \mathrm{mg} / \mathrm{kg}$. The value of $\mathrm{AUC}_{0}$ to 4 was zero at all doses because only one patient provided quantifiable values at each dose level. The pharmacokinetics profile of GSK933776 was variable in the CSF and did exhibit a dose-response relationship.

For plasma pharmacokinetics, following intravenous infusion of GSK933776 at the $1 \mathrm{mg} / \mathrm{kg}, 3 \mathrm{mg} / \mathrm{kg}$ and 6 $\mathrm{mg} / \mathrm{kg}$ doses, $C_{\max }$ values were $18.4 \mu \mathrm{g} / \mathrm{ml}, 104.0 \mu \mathrm{g} / \mathrm{ml}$ and $158.2 \mu \mathrm{g} / \mathrm{ml}$, and $t_{\max }$ values were 11.7 hours, 2.1 hours and 1.9 hours, respectively (Table 4). GSK933776 exposure appeared to increase with dose level (Table 4).

A delay in the detection of GSK933776 in CSF was observed (median values of each dose group from 5.0 hours to 8.5 hours) compared with GSK933776 in plasma, which was detected immediately. This delay was reflected in the CSF/plasma ratios, which increased with time and were in the range of 0 to $0.23 \%$. There were no relationships between changes from baseline in CSF A $\beta$ 


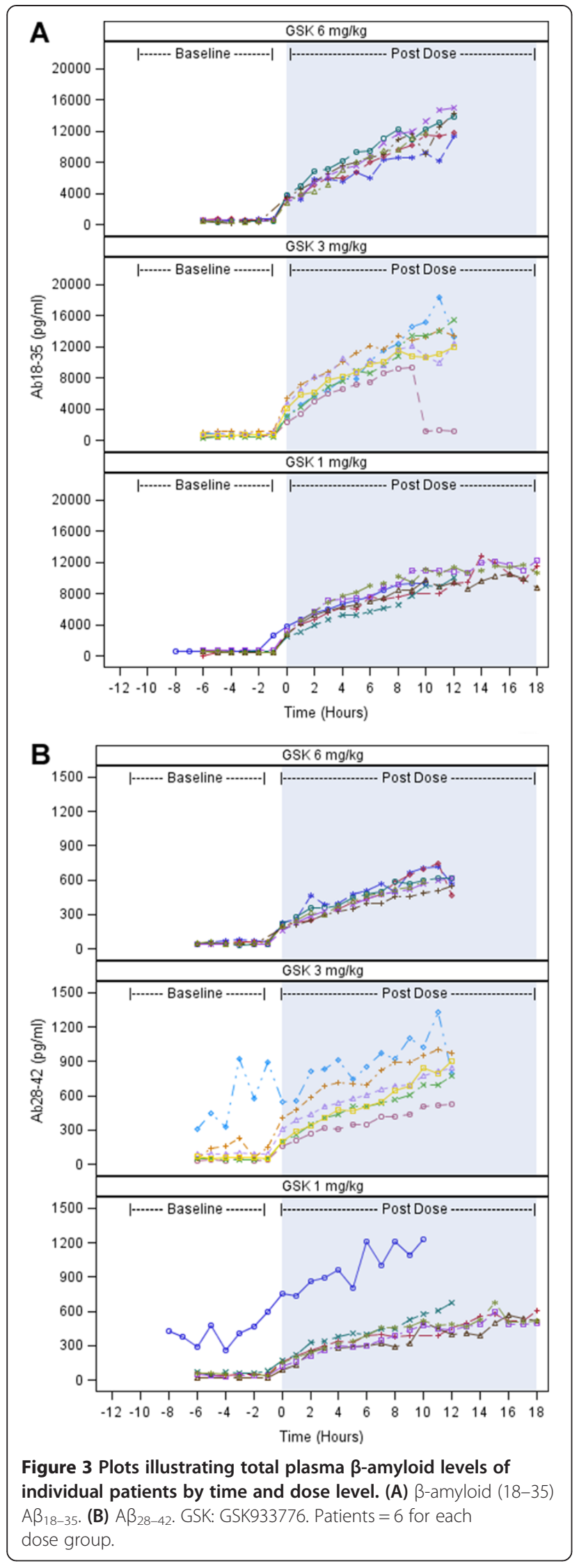

and any of the CSF pharmacokinetics parameters. Therefore, no PK/PD modelling was performed.

\section{Safety}

A summary of the most frequently reported adverse events is given in Table 5. Two patients experienced serious adverse events, neither of which was considered by the investigator to be related to GSK933776. One patient who received $3 \mathrm{mg} / \mathrm{kg}$ GSK933776 experienced a procedure-related headache that started approximately 5.5 hours before administration of GSK933776. That 73-year-old patient was unable to eat and drink, was admitted to the hospital 5 days later and was given intravenous fluids and pain relief medication, and the headache resolved 8 days later. One patient required surgical treatment to remove part of a catheter that tore during placement and therefore did not receive GSK933776. That patient was admitted to the neurosurgery ward, and the disrupted piece of the catheter was removed after incision of the skin. The catheter was broken in soft tissue, and no subsequent infection or other complications occurred. The adverse event thus resolved, and the patient was discharged from the hospital the following day and was withdrawn from the study. No clinical laboratory values were reported as adverse events. One patient experienced two episodes of atrial fibrillation during GSK933776 treatment, neither of which was considered to be related to GSK933776 administration. One patient who received GSK933776 $(6 \mathrm{mg} / \mathrm{kg})$ had positive results in the binding antibody and neutralising antibody tests at the follow-up visit 56 days after the first dose.

\section{Discussion}

Our findings in this study support target engagement of GSK933776 in CSF. The patients' baseline levels of CSF $\mathrm{A} \beta_{1-42}$ were stable, and there were apparent decreases following all doses of GSK933776 from baseline in CSF $A \beta_{1-42}$. These decreases seem to have been dosedependent, with greater reductions associated with higher doses of GSK933776, and time-dependent, with greater reductions occurring 5 hours after administration. In contrast to a previous study, no diurnal variation in CSF $\mathrm{A} \beta$ levels was observed [14]. CSF tau levels increased slightly during this study, but the reason for this is unknown. It could be related to the total volume of CSF sampled and mobilisation of ventricular CSF to the lumbar sac. Tau concentrations in ventricular CSF are about five times higher than in lumbar CSF [15].

We observed an increase in both total $A \beta_{18-35}$ and total $\mathrm{A} \beta 42_{28-42}$ concentrations in plasma following GSK933776 treatment. The pharmacokinetics data confirmed the presence of GSK933776 in CSF, which suggests a central mechanistic model of action rather than a peripheral sink mechanism. Although these two theories 
Table 3 Noncompartmental pharmacokinetics in cerebrospinal fluid by dose following single dosing with GSK933776 ${ }^{\mathrm{a}}$

\begin{tabular}{|c|c|c|c|}
\hline \multirow[t]{2}{*}{ Parameters } & \multicolumn{3}{|c|}{ Median (range) } \\
\hline & $1 \mathrm{mg} / \mathrm{kg}(N / n=6 / 3)$ & $3 \mathrm{mg} / \mathrm{kg}(N / n=6 / 6)$ & $6 \mathrm{mg} / \mathrm{kg}(N / n=6 / 4)$ \\
\hline $\mathrm{AUC}_{0-4}(\mathrm{~h} \cdot \mathrm{mg} / \mathrm{ml})$ & $0.0(0.0$ to 71.1$)$ & $0.0(0.0$ to 32.1$)$ & 0.0 (0.0 to 38.9$)$ \\
\hline $\mathrm{AUC}_{5-12}(\mathrm{~h} \cdot \mathrm{mg} / \mathrm{ml})$ & 87.9 (12.7 to 134.9$)$ & 54.8 (6.3 to 398.8$)$ & 140.2 (49.1 to 626.5) \\
\hline $\mathrm{AUC}_{0-12}(\mathrm{~h} \cdot \mathrm{mg} / \mathrm{ml})$ & 87.9 (12.7 to 210.9) & $54.8(6.3$ to 456.0$)$ & 140.2 (49.1 to 703.9$)$ \\
\hline$A \cup C_{0-t}(h \cdot m g / m l)$ & 6.3 (0.0 to 339.5) & $54.8(6.3$ to 456.0$)$ & 88.1 (0.0 to 703.9 ) \\
\hline$C_{\max }(\mu \mathrm{g} / \mathrm{ml})$ & 12.7 (0.0 to 47.8 ) & 20.1 (12.5 to 84.1) & 28.5 (0.0 to 116.9) \\
\hline$C_{t}(\mu \mathrm{g} / \mathrm{ml})$ & 19.0 (11.4 to 25.3$)$ & $19.6(12.5$ to 84.1$)$ & 47.9 (18.6 to 116.1$)$ \\
\hline$t_{\max }(\mathrm{h})$ & $10.0(2.0$ to 11.0$)$ & 11.8 (10.0 to 12.0$)$ & $12.0(11.0$ to 12.0$)$ \\
\hline$t_{\text {last }}(\mathrm{h})$ & $17.0(11.0$ to 19.0$)$ & $12.0(11.6$ to 12.0$)$ & 12.0 (12 to 12$)$ \\
\hline$t_{\operatorname{lag}}(\mathrm{h})$ & $8.0(0.0$ to 10.0$)$ & 8.5 (2.0 to 11.0$)$ & 5.0 (2.0 to 8.0$)$ \\
\hline
\end{tabular}

are popular in the mechanism of action of $\mathrm{AD}$ vaccination, they are not mutually exclusive. Further studies are required to characterise the mechanistic model of GSK933776 mode of action early and late after treatment.

The findings regarding GSK933776 plasma pharmacokinetics in this study are consistent with those in previous solanezumab single- and multiple-dose studies $[5,16]$. In all of these studies, maximum drug plasma concentrations increased with drug dose levels $[5,16]$. Also, long terminal elimination half-lives were observed, which is typical of a monoclonal antibody with low plasma clearance. $\mathrm{AUC}_{0-\infty}$ and $t_{1 / 2}$ values were not calculated in this study, because more samples would have been required to characterise adequately the switch from the first to the terminal exponential phase. In a previous study of GSK9933776, however, a long terminal elimination half-life (average range: 10 to 15 days) was observed (manuscript in submission). The increase in plasma levels of total $A \beta_{18-35}$ and $A \beta_{28-42}$ did not exhibit an apparent dose-response relationship during the short observation time in this study.
This study confirms the presence of GSK933776 in CSF. CSF versus plasma ratios increased with time and were ranged from 0 to $0.23 \%$, reflecting the delay of detection of GSK933776 in CSF by 5.0 hours to 8.5 hours (median values in dose groups).

This study has several limitations. The decreases from baseline in CSF $A \beta_{1-42}$ were greater with the higher dose of GSK933776 (6 mg/kg) than with the $1 \mathrm{mg} / \mathrm{kg}$ and $3 \mathrm{mg} / \mathrm{kg}$ dose groups. However, this result might have been driven by the higher baseline CSF $A \beta_{1-42}$ values in the $6 \mathrm{mg} / \mathrm{kg}$ group compared with the other groups. Differing baseline CSF $A \beta_{1-42}$ values were also observed between the other dose groups. However, all dose groups showed similar trends in CSF $A \beta_{1-42}$ changes over time, regardless of baseline CSF $A \beta_{1-42}$ values, suggesting that this limitation did not affect the interpretability of the data. This study also has a small sample size and is not formally powered; therefore, we conducted no formal statistical analyses. Despite the feasibility-driven limited sample size in this study, our sample size is similar to those of other published studies in the field [6,7]. In

Table 4 Noncompartmental pharmacokinetics in plasma following single dosing with GSK933776 ${ }^{\mathrm{a}}$

\begin{tabular}{|c|c|c|c|c|c|c|}
\hline \multirow[b]{2}{*}{ Parameters } & \multicolumn{6}{|c|}{ Geometric mean (CV in \%) } \\
\hline & $1 \mathrm{mg} / \mathrm{kg}(N / n=6 / 6)$ & $95 \% \mathrm{Cl}$ & $3 \mathrm{mg} / \mathrm{kg}(N / n=6 / 6)$ & $95 \% \mathrm{Cl}$ & $6 \mathrm{mg} / \mathrm{kg}(N / n=6 / 6)$ & $95 \% \mathrm{Cl}$ \\
\hline $\mathrm{AUC}_{0-12}(\mathrm{~h} \cdot \mathrm{mg} / \mathrm{ml})$ & $0.2(26.0)$ & 0.1 to 0.2 & $1.0(19.5)$ & 0.9 to 1.3 & $1.6(20.6)$ & 1.3 to 2.0 \\
\hline$A \cup C_{0-t}(h \cdot m g / m l)$ & $3.3(39.3)$ & 2.2 to 4.9 & $23.0(12.8)$ & 20.2 to 26.3 & $36.3(15.3)$ & 31.0 to 42.6 \\
\hline$C_{\max }(\mu \mathrm{g} / \mathrm{ml})$ & $18.4(29.0)$ & 13.6 to 24.9 & $104.0(20.0)$ & 84.4 to 128.1 & $158.2(24.0)$ & 123.8 to 202.1 \\
\hline$C_{t}(\mu \mathrm{g} / \mathrm{ml})$ & $0.5(366.0)$ & 0.1 to 2.5 & $1.2(33.0)$ & 0.9 to 1.7 & $1.5(30.0)$ & 1.1 to 2.1 \\
\hline$t_{\text {last }}(\mathrm{h})$ & $909.8(105.5)$ & 367.0 to $2,255.4$ & $1,337.4(0.2)$ & $1,335.1$ to $1,339.8$ & $1,417.2(7.0)$ & $1,317.6$ to $1,524.3$ \\
\hline$t_{\max }(h)$ & $11.7(264.1)$ & 2.6 to 53.1 & $2.1(16.4)$ & 1.8 to 2.5 & $1.9(61.2)$ & 1.1 to 3.4 \\
\hline
\end{tabular}

${ }^{a} \mathrm{AUC}_{0-12}$ : Area under the plasma concentration-time curve from time 0 to 12 hours postdosing; $\mathrm{AUC}_{0-t}$ : Area under the plasma concentration-time curve to the last quantifiable concentration; $\mathrm{Cl}$ : Confidence interval; $C_{\text {max }}$ : Maximum plasma concentration; $C_{\mathrm{t}}$ : Concentration at $t_{\text {last }}$ CV: Coefficient of variation; $t_{\text {last }}$ : Time of last observed plasma concentration; $t_{\max }$ : Time of occurrence of $C_{\max }$. 
Table 5 Summary of the most frequently reported adverse events $^{a}$

\begin{tabular}{|c|c|c|c|}
\hline \multirow[b]{2}{*}{ Adverse events } & \multicolumn{3}{|c|}{ GSK933776 dose } \\
\hline & $\begin{array}{l}1 \mathrm{mg} / \mathrm{kg} \\
(N / n=6 / 6)\end{array}$ & $\begin{array}{l}3 \mathrm{mg} / \mathrm{kg} \\
(N / n=6 / 6)\end{array}$ & $\begin{array}{l}6 \mathrm{mg} / \mathrm{kg} \\
(\mathrm{N} / \mathrm{n}=6 / 6)\end{array}$ \\
\hline Any event & $3(50)$ & $5(83)$ & $5(83)$ \\
\hline Fatigue & 0 & $2(33)$ & $2(33)$ \\
\hline Headache & $1(17)$ & $4(67)$ & $2(33)$ \\
\hline Nausea & 0 & $3(50)$ & $1(17)$ \\
\hline Vomiting & 0 & $2(33)$ & $1(17)$ \\
\hline Back pain & $1(17)$ & $2(33)$ & $1(17)$ \\
\hline Nasopharyngitis & 0 & 0 & 0 \\
\hline Neck pain & 0 & $1(17)$ & $1(17)$ \\
\hline Atrial fibrillation & $1(17)$ & 0 & $1(17)$ \\
\hline Procedural headache & 0 & 1 (17) & $1(17)$ \\
\hline
\end{tabular}

${ }^{\mathrm{a} D a t a}$ in parentheses are percentages.

addition, it is unknown to what extent GSK933776 may have interfered with $A \beta$ in the CSF $A \beta_{1-42}$ assay. The potential for spurious results induced by any possible interaction of GSK933776 with the CSF $A \beta_{1-42}$ assay was not assessed, thus limiting the interpretation of the results. However, there was no apparent relationship between changes from baseline in CSF A $\beta$ and any CSF pharmacokinetics parameters. The differences in mean baseline CSF $A \beta$ levels observed between the dose groups were most likely due to chance resulting from the small sample size.

The observed frequency of $A P O E \& 4$ carriers was higher in this study (14 (93\%) of 15 patients) than in a typical AD population (64.8\%) [17]. This difference could be due to the small number of patients in this study and the screening selection criteria pertaining to reductions in $A \beta$ and increases in tau levels in the CSF. Other contributing factors could be the age of the patients and/or the MMSE score ranges. In this study, no $A P O E \& 4$ data were obtained from patients who failed screening, because pharmacogenetic samples were taken only from patients who were randomised.

We believe that, to the best of our knowledge, this study is one of very few intervention studies in which the feasibility of using the CSF catheter to assess shortterm $A \beta$ changes has been investigated. One catheterrelated serious adverse event occurred during the catheter insertion procedure in our study.

The outcomes of phase III studies conducted with the A $\beta$ monoclonal antibodies bapineuzumab and gantenerumab, as well as another pivotal study carried out with solanezumab, have failed to demonstrate unambiguous efficacy in patients with mild to moderate AD, but they have triggered significant new activity in the study of earlier stages of AD.

\section{Conclusions}

The results of this study support pharmacological activity and target engagement of GSK933776 in both CSF and plasma. They demonstrate that the continuous sampling method using a catheter can be used successfully to assess $A \beta$ changes after single-dose administration of an anti-A $\beta$ antibody in patients with mild AD or MCI.

\section{Additional files}

Additional file 1: Individual patient plots of cerebrospinal fluid tau by time and dose level. GSK: GSK933776. Coloured dashed lines refer to each individual patient plot.

Additional file 2: Individual patient plots of cerebrospinal fluid phosphorylated tau 181 by time and dose level. GSK: GSK933776; P-TAU: Phosphorylated tau. Coloured dashed line refers to each individual patient plot.

\section{Abbreviations}

AD: Alzheimer's disease; $A \beta$ : $\beta$-amyloid; $\mathrm{AUC}_{0-12}$ : Area under the plasma and cerebral spinal fluid concentration-time curve from time 0 to 12 hours postdosing; $\mathrm{AUC}_{0-4}$ : Area under the cerebral spinal fluid concentration-time curve from time 0 to 4 hours postdosing; $A \cup C_{0-t:}$ : Area under the plasma and cerebral spinal fluid concentration-time curve to the last quantifiable concentration; $\mathrm{AUC}_{5-12}$ : Area under the plasma and cerebral spinal fluid concentration time curve from 5 hours to 12 hours postdosing; $C_{\text {max }}$ : First occurrence of the maximum observed plasma and cerebral spinal fluid concentration determined directly from raw concentration time data; CNS: Central nervous system; CSF: Cerebrospinal fluid; $C_{\mathrm{t}}$ : Concentration at tlasti ECG: Electrocardiogram; MCl: Mild cognitive impairment; MMSE: Mini Mental State Examination; MRI: Magnetic resonance imaging; $t_{\text {lag: }}$ : Time prior to the first measurable (nonzero) concentration in cerebral spinal fluid; $t_{\text {last: }}$ :Time of the last observed plasma concentration; $t_{\max }$ : Time at which $C_{\max }$ was observed determined directly from raw concentration time data.

\section{Competing interests}

MS, XT, AY, SK, AL, MC, CH, JH and PM are GlaxoSmithKline employees. This study was funded by GlaxoSmithKline. TL, NA, AR, CAFvA and HZ were sponsored by GlaxoSmithKline. GlaxoSmithKline sponsored and paid for this study.

\section{Authors' contributions}

$T L$ participated in the recruitment of study participants, partly performed the study and reviewed the data. AL participated in the acquisition, analysis and interpretation of pharmacodynamic data. $\mathrm{HZ}$ contributed to the study concept and design, biochemical analyses and critical review of the manuscript for important intellectual content. AY participated in the delivery and interpretation of genetic data (APOE $\varepsilon 4$ ). XT contributed to the study concept and design, partly performed the study and acquired the data. NA participated in the study design, performed the study and obtained and interpreted the data. CAFvA participated in the recruitment of study participants, partly performed the study and reviewed the data. SK was the project manager and reviewed patient data. AR generated and reviewed patient data. MC reviewed safety data. PM participated in the design of the study, performed statistical analyses and provided interpretation of the data. $\mathrm{CH}$ contributed to and reviewed the pharmacokinetics bioanalytical data. MS performed mathematical analysis and reviewed pharmacokinetic data. $\mathrm{JH}$ contributed to the design and conduct of the study. All authors read and approved the final manuscript.

\section{Acknowledgements}

We would like to thank the patients and their caregivers for their dedication to and participation in the study. We would also like to thank Pia Lisjo and Göran Larsson from GlaxoSmithKline AB, Sweden, and Dr Ulf Niess from GlaxoSmithKline GmbH \& Co KG, Germany. In addition, we thank Kenneth Sutton of Genetics, GlaxoSmithKline, for generating the APOE genotyping data and Frances Murray for data management. Dr Susan Reijntjes of Niche 
Science and Technology provided writing and editorial support during the development of the manuscript.

\section{Author details}

'Department of Psychiatry and Psychotherapy, University Hospital of Tübingen, Calwerstrasse 14, D-72076 Tübingen, Germany. ${ }^{2}$ Center of Old Age Psychiatry, Psychiatric University Hospital, Wilhelm Klein-Strasse 27, CH-4012 Basel, Switzerland. ${ }^{3}$ Karolinska Institute, Alzheimer Research Centre, Solnavägen 1, 17177 Solna, Stockholm Sweden. ${ }^{4}$ Quantitative Sciences, GlaxoSmithKline, Stockley Park West, 1-3 Iron Bridge Road, Uxbridge, Middlesex UB11 1BT, UK. ${ }^{5}$ Department of Neurology, University Hospital RWTH Aachen, Pauwelstrasse 30, Aachen, Germany. ${ }^{6}$ Department of Neurology, Ulm University, Oberer Eselsberg 45, 89081 Ulm, Germany. ${ }^{7}$ Clinical Pharmacology Sciences \& Study Operations, GlaxoSmithKline, Gunnels Wood Road, Stevenage, Hertfordshire SG1 2NY, UK. ${ }^{8}$ Genetics, GlaxoSmithKline, Gunnels Wood Road, Stevenage, Hertfordshire SG1 2NY, UK. ${ }^{9}$ Clinical Immunology, GlaxoSmithKline, Upper Merion, 709 Swedeland Road, King of Prussia, PA 19406, USA. ${ }^{10} \mathrm{Global}$ Clinical Safety and Pharmacovigilance, GlaxoSmithKline, Stockley Park West, 1-3 Iron Bridge Road, Uxbridge, Middlesex UB11 1BT, UK. ${ }^{11}$ Drug Metabolism and Pharmacokinetics, GlaxoSmithKline, Upper Merion, 709 Swedeland Road, King of Prussia, PA 19406, USA. ${ }^{12}$ Department of Psychiatry and Neurochemistry, Clinical Neurochemistry Laboratory, Institute of Neuroscience and Physiology, The Sahlgrenska Academy at University of Gothenburg, V-husek Mölndal, SE-431 80, Sweden. ${ }^{13}$ UCL Institute of Neurology, Queen Square, London WC1N 3BG, UK. ${ }^{14}$ Neurosciences Therapeutic Area, GlaxoSmithKline, 898 Halei Road, Zhangjiang Hi-Tech Park, Shanghai, 201203, People's Republic of China. ${ }^{15}$ Quantitative Sciences, GlaxoSmithKline, Gunnels Wood Road, Stevenage, Hertfordshire SG1 2NY, UK.

Received: 13 December 2013 Accepted: 17 March 2014 Published: 9 April 2014

\section{References}

1. Selkoe DJ: Alzheimer's disease: genes, proteins, and therapy. Physio/ Rev 2001, 81:741-766.

2. Greenberg SM, Frosch MP: Life imitates art: anti-amyloid antibodies and inflammatory cerebral amyloid angiopathy. Neurology 2011, 76:772-773.

3. DeMattos RB, Bales KR, Cummins DJ, Dodart JC, Paul SM, Holtzman DM: Peripheral anti-A $\beta$ antibody alters CNS and plasma $A \beta$ clearance and decreases brain $A \beta$ burden in a mouse model of Alzheimer's disease. Proc Natl Acad Sci U S A 2001, 98:8850-8855.

4. Ostrowitzki S, Deptula D, Thurfjell L, Barkhof F, Bohrmann B, Brooks DJ, Klunk WE, Ashford E, Yoo K, Xu ZX, Loetscher H, Santarelli L: Mechanism of amyloid removal in patients with Alzheimer disease treated with gantenerumab. Arch Neurol 2012, 69:198-207.

5. Farlow M, Arnold SE, van Dyck CH, Aisen PS, Snider BJ, Porsteinsson AP, Friedrich S, Dean RA, Gonzales C, Sethuraman G, DeMattos RB, Mohs R, Paul SM, Siemers ER: Safety and biomarker effects of solanezumab in patients with Alzheimer's disease. Alzheimers Dement 2012, 8:261-271.

6. Bateman RJ, Siemers ER, Mawuenyega KG, Wen G, Browning KR, Sigurdson WC, Yarasheski KE, Friedrich SW, Demattos RB, May PC, Paul SM, Holtzman DM: $A$-secretase inhibitor decreases amyloid- $\beta$ production in the central nervous system. Ann Neurol 2009, 66:48-54.

7. Mawuenyega KG, Sigurdson W, Ovod V, Munsell L, Kasten T, Morris JC, Yarasheski KE, Bateman RJ: Decreased clearance of CNS $\beta$-amyloid in Alzheimer's disease. Science 2010, 330:1774.

8. Folstein MF, Folstein SE, McHugh PR: "Mini-mental state": a practical method for grading the cognitive state of patients for the clinician. J Psych Research 1975, 12:189-198.

9. Sjögren M, Vanderstichele H, Agren H, Zachrisson I, Edsbagge M, Wikkelsø C, Skoog I, Wallin A, Wahlund LO, Marcusson J, Nägga K, Andreasen N, Davidsson $P$, Vanmechelen $E$, Blennow K: Tau and $A \beta 42$ in cerebrospinal fluid from healthy adults 21-93 years of age: establishment of reference values. Clin Chem 2001, 47:1776-1781.

10. Zetterberg H, Wahlund LO, Blennow K: Cerebrospinal fluid markers for prediction of Alzheimer's disease. Neurosci Lett 2003, 352:67-69.

11. Dubois B, Feldman HH, Jacova C, DeKosky ST, Barberger-Gateau P, Cummings J, Delacourte A, Galasko D, Gauthier S, Jicha G, Meguro K, O'Brien J, Pasquier F, Robert P, Rossor M, Salloway S, Stern Y, Visser PJ, Scheltens P:
Research criteria for the diagnosis of Alzheimer's disease: revising the NINCDS-ADRDA criteria. Lancet Neurol 2007, 6:734-746.

12. Dubois B, Feldman HH, Jacova C, Cummings IL, DeKosky ST, Barberger-Gateau P, Delacourte A, Frisoni G, Fox NC, Galasko D, Gauthier S, Hampel H, Jicha GA, Meguro K, O'Brien J, Pasquier F, Robert P, Rossor M, Salloway S, Sarazin M, de Souza LC, Stern Y, Visser PJ, Scheltens P: Revising the definition of Alzheimer's disease: a new lexicon. Lancet Neurol 2010, 9:1118-1127.

13. Albert MS, DeKosky ST, Dickson D, Dubois B, Feldman HH, Fox NC, Gamst A, Holtzman DM, Jagust WJ, Petersen RC, Snyder PJ, Carrillo MC, Thies B, Phelps $\mathrm{CH}$ : The diagnosis of mild cognitive impairment due to Alzheimer's disease: recommendations from the National Institute on Aging-Alzheimer's Association workgroups on diagnostic guidelines for Alzheimer's disease. Alzheimers Dement 2011, 7:270-279.

14. Huang Y, Potter R, Sigurdson W, Santacruz A, Shih S, Ju YE, Kasten T, Morris JC, Mintun M, Duntley S, Bateman RJ: Effects of age and amyloid deposition on $A \beta$ dynamics in the human central nervous system. Arch Neurol 2012, 69:51-58.

15. Jeppsson A, Zetterberg H, Blennow K, Wikkelsø C: Idiopathic normal-pressure hydrocephalus: pathophysiology and diagnosis by CSF biomarkers. Neurology 2013, 80:1385-1392.

16. Siemers ER, Friedrich S, Dean RA, Gonzales CR, Farlow MR, Paul SM, Demattos RB: Safety and changes in plasma cerebrospinal fluid amyloid $\beta$ after a single administration of an amyloid $\beta$ monoclonal antibody in subjects with Alzheimer disease. Clin Neuropharmacol 2010, 33:67-73.

17. Crean S, Ward A, Mercaldi CJ, Collins JM, Cook MN, Baker NL, Arrighi HM: Apolipoprotein E \&4 prevalence in Alzheimer's disease patients varies across global populations: a systematic literature review and meta-analysis. Dement Geriatr Cogn Disord 2011, 31:20-30.

\section{doi:10.1186/alzrt249}

Cite this article as: Leyhe et al:: Modulation of $\beta$-amyloid by a single dose of GSK933776 in patients with mild Alzheimer's disease: a phase I study. Alzheimer's Research \& Therapy 2014 6:19.

\section{Submit your next manuscript to BioMed Central and take full advantage of:}

- Convenient online submission

- Thorough peer review

- No space constraints or color figure charges

- Immediate publication on acceptance

- Inclusion in PubMed, CAS, Scopus and Google Scholar

- Research which is freely available for redistribution

Submit your manuscript at www.biomedcentral.com/submit
C Biomed Central 